
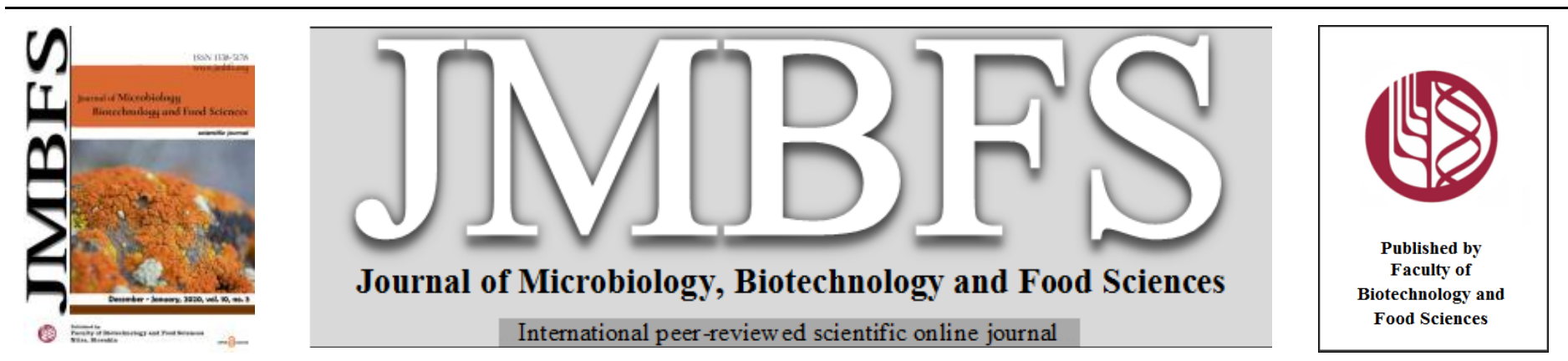

\title{
RESPONSE SURFACE METHODOLOGY BASED MEDIUM OPTIMIZATION FOR IMPROVEMENT OF CHOLESTEROL OXIDASE ENZYME PRODUCTION BY NEWLY ISOLATED STREPTOMYCES SP.
}

\author{
Nayera A.M. Abdelwahed ${ }^{1 *}$, Amira A. Gamal ${ }^{1}$, Shaymaa A. Ismail ${ }^{1}$, Amira A. Hassan ${ }^{1}$
}

$\operatorname{Address(es):~}$

${ }^{1}$ Chemistry of Natural and Microbial Products Department, National Research Centre, 33 El Bohouth st.(former El Tahrir st.), P.O 12622, Dokki, Giza, Egypt.

*Corresponding author: niarawahed@yahoo.com

doi: 10.15414/jmbfs.2020.10.8.374-380

\section{ARTICLE INFO}

Received 27. 12. 2019

Revised 9. 7. 2020

Accepted 13. 7. 2020

Published 1. 12. 2020

Regular article open $\partial_{\text {ACCESS }}$

\begin{abstract}
Cholesterol oxidase is an important enzyme with great commercial value in many clinical and industrial processes, such as determination of cholesterol levels in food, serum and other clinical samples as well as its potential application, as a biocatalyst for bioconversion of sterol compounds and as an insecticide. A Preliminary comparative study of cholesterol oxidase enzyme production from Streptomyces sp. strain NHIA_CH5 using six different media containing cholesterol in submerged fermentation was investigated. An increase in the production was detected after two days in all of the studied media with a maximum production of $23.7 \mathrm{U} / \mathrm{mL}$, noticed in medium containing soluble starch, glucose, peptone, beef extract, $\mathrm{MgSO}_{4} .7 \mathrm{H}_{2} \mathrm{O}$, and $\mathrm{NaCl}$. A classical (one-variable-at-a-time) method revealed that the elimination of $\mathrm{MgSO}_{4} \cdot 7 \mathrm{H}_{2} \mathrm{O}$ and $\mathrm{NaCl}$ favored cholesterol oxidase enzyme production. Statistical optimization of the other components was studied using the screening method Plackett-Burman design followed by the modeling method of the central composite design (CCD). The results showed that beef extract and glucose are the variables that significantly influenced and considered as the most important factors for cholesterol oxidase production. Experiments of CCD based on response surface methodology determine the optimum concentrations of these significant medium components and revealed maximum cholesterol oxidase enzyme production $(50.5 \mathrm{U} / \mathrm{mL})$ at beef extract $55 \mathrm{~g} / \mathrm{L}$ and glucose $40 \mathrm{~g} / \mathrm{L}$ which represented 2- fold higher titers than acquired from the non-optimized medium.
\end{abstract}

Keywords: Streptomyces sp., cholesterol oxidase, optimization, statistical design

\section{INTRODUCTION}

Cholesterol oxidase enzyme ( $\mathrm{CHO})$ is a bacterial enzyme that serves as catalysts for the initial step in the degradation of cholesterol (Devi \& Kanwar, 2017). The enzyme belongs to oxidoreductase family and it has several potential applications, as a biocontrol in the agricultural industry. However, in pathogenic bacteria, it acts as a membrane-damaging factor and therefore contributes as a virulence factor in the pathogenicity of these bacteria (Brzostek et al., 2007). Additionally, it can be used to produce steroidal intermediates which are precursors for the chemical synthesis of steroid hormones (Ghosh et al., 2018). The CHO is a biotechnologically important enzyme and is being used for the determination of cholesterol in blood serum and food (Khan et al., 2009), as well as, it is assumed potential in the manufacture of diets with reduced cholesterol. There is a growing demand for exploitation safe sources of enzyme favorable for industrial applications in food industry, agriculture, and medicine (Niwas et al., 2013). Streptomycetes generally produce the enzyme in an extracellular manner therefore they are widely recognized as preferable enzyme sources since they facilitate the enzyme recovery from the fermentation broth (Mukhtar et al., 2017). S. violascens, $S$. parvus, and $S$. fradiae have been reported from Streptomyces sp., to possess more advantageous properties than those from other microorganisms in the production of $\mathrm{CHO}$ in term of low production cost, longer shelf life and stability (Srivastava et al., 2018a). In this regard, the yield could be increased by optimizing media components in the basal medium to ensure enhancing the production of the desired metabolite. The nutritional requirements can be controlled for the optimization of enzymatic processes by traditional or statistical approaches. The conventional one-factor-at-a-time (OFAT) optimization method is a method of designing experiments involving the testing of factors, varying a single independent factor while keeping others fixed (Sakkas et al., 2010). The major advantage of OFAT is the simplicity to gain information about one factor in each experimental trial and results can be analyzed by using simple graphs (Singh $\boldsymbol{e t}$ al., 2017). Many attempts were applied to obtain massive production of enzymes using the conventional nonstatistical (OFAT) approach as a first step in medium optimization as to get $\mathrm{CHO}$ from Streptomyces rimosus (Srivastava et al., 2018b) and Streptomyces rochei NAM-19 (Elsayed \& Nayera, 2020), L-methioninase from bacterium Hafnia alvei (Alshehri, 2020) and $\beta$-galactosidase from Lactobacillus leichmannii 313 (Deng et al., 2020). However, this method ignores the combined interaction(s) among various nutritional parameters and is not only time restrictive, but also more runs are required when several variables are to be considered. The application of statistical tools such, as Plackett-Burman design (PBD) and response surface methodology (RSM) could overcome these restrictions (Rajeswari et al., 2015; Abdelwahed et al., 2017). They are helpful models for the examination of the effects of medium components concentrations for rapid fermentations during the process of enzyme production and have been applied successfully for optimization of nutritional media constituents to improve the production of metabolites (Singh et al., 2011; Hashem et al., 2018; Abdelwahed et al., 2014). An increase in enzyme production reduces the overall cost of the product, as well as the production cost; hence, the objective of this study was an attempt to improve $\mathrm{CHO}$ production using a potent local isolate through optimization of media composition in submerged cultures.

\section{MATERIALS AND METHODS}

\section{Microbial strain and fermentation conditions}

The new actinomycete isolate from Egyptian soil previously identified in our lab as Streptomyces sp. strain NHIA_CH5 deposited to GenBank under accession number MK680300.1 was maintained on slopes containing modified starch-nitrate agar medium of the following composition $(\mathrm{g} / \mathrm{L})$ : Starch $20 ; \mathrm{KNO}_{3} 2 ; \mathrm{K}_{2} \mathrm{HPO}_{4} 1$; $\mathrm{MgSO}_{4} .7 \mathrm{H}_{2} \mathrm{O} 0.5 ; \mathrm{CaCO}_{3} 3$; agar 20 and $\mathrm{pH}$ 7. Slopes will be incubated for a period of 10 days at $32{ }^{\circ} \mathrm{C}$. The isolate was stored as spore suspensions in $20 \%$ $(\mathrm{v} / \mathrm{v})$ glycerol at $-20{ }^{\circ} \mathrm{C}$ for subsequent investigation. The seed culture was prepared by inoculating $50 \mathrm{~mL}$ starch-nitrate broth medium as mentioned above with a loop full slant culture, then incubated at $32{ }^{\circ} \mathrm{C}$ for $48 \mathrm{~h}$. with shaking at 200 $\mathrm{rpm}$ thereafter two percent $(\mathrm{v} / \mathrm{v})$ of the seed culture was transferred to $50 \mathrm{~mL}$ of the production medium. 


\section{Enzyme assay}

The enzymatic activity assay of $(\mathrm{CHO})$ is based on the conversion of cholesterol to 4-cholestene-3-one. The assay was performed by following the method of Allain et al., (1974) where hydrogen peroxide couples with 4-aminoantipyrine and phenol to produce quinoneimine dye showing maximum absorption at 500 $\mathrm{nm}$. The reaction buffer was prepared by adding $19.8 \mathrm{mM}$ phenol and $1.5 \mathrm{mM} 4$ aminoantipyrine in $94 \mathrm{mM}$ potassium phosphate buffer $(\mathrm{pH} \mathrm{7.0)}$. A reaction mixture $(3.03 \mathrm{~mL})$ was prepared by adding $2.8 \mathrm{ml}$ of above-stated phenol, $0.2 \mathrm{ml}$ of $0.9 \mathrm{mM}$ cholesterol (dissolved in $1 \mathrm{~mL}$ of $0.35 \%$ Triton X-100), $0.01 \mathrm{ml}$ of 19 units of peroxidase from horseradish and $0.02 \mathrm{~mL}$ of the enzyme solution. The reaction was performed at $37^{\circ} \mathrm{C}$ for $10 \mathrm{~min}$ and terminated by heating at $100{ }^{\circ} \mathrm{C}$ for $5 \mathrm{~min}$. The reaction mixture was cooled at room temperature $\left(25^{\circ} \mathrm{C}\right)$ and the rate of reaction of product (4-cholesten-3-one) formation was determined by measuring the color developed at $500 \mathrm{~nm}$. One unit of $\mathrm{CHO}$ has been defined as the quantity of the enzyme required to produce $1.0 \mu \mathrm{mol}$ of 4-cholesten-3-one per $\min$ at $\mathrm{pH} 7.0$ and $37^{\circ} \mathrm{C}$. The concentration of the protein/enzyme was measured by the method of (Lowry et al., 1951) using bovine serum albumin (BSA) as a standard.

\section{Determination of specific activity}

To evaluate the production process of the enzyme, the given equation was used to measure the specific activity: Specific activity $(\mathrm{U} / \mathrm{mg})=$ Total activity $(\mathrm{U} / \mathrm{mL}) /$ Total Protein (mg/mL) as reported by Lin et al., (2009).

\section{Effect of different media for the production of $\mathrm{CHO}$}

Production of $\mathrm{CHO}$ was investigated through different media selected from the works of literature and the one giving maximum enzyme activity was used for further analysis. The screening of the production media composed of nutrients in (g/L) was as follow: Medium (1): glucose, 4; yeast extract, 4; malt extract, 10 and $\mathrm{CaCO}_{3}, 2$ (Niwas et al., 2013). Medium (2): malt extract, 2; glucose, 15 ; yeast extract, 4; peptone, 5; $\mathrm{K}_{2} \mathrm{HPO}_{4}, 1 ; \mathrm{MgSO}_{4} .7 \mathrm{H}_{2} \mathrm{O}, 0.5$ and $\mathrm{NaCl}, 0.5$ (Niwas et al., 2013). Medium (3): soluble starch, 10; glucose, 10; peptone, 6; yeast extract, 5; $\mathrm{K}_{2} \mathrm{HPO}_{4}, 1 ; \mathrm{MgSO}_{4} .7 \mathrm{H}_{2} \mathrm{O}, 0.5 ; \mathrm{NaCl}, 0.5$ (Tabatabaei et al., 2001). Medium (4): soluble starch, 15; yeast extract, 4; malt extract, 2; peptone, $0.5 ; \mathrm{K}_{2} \mathrm{HPO}_{4}, 1$; $\mathrm{MgSO}_{4} 7 \mathrm{H}_{2} \mathrm{O}, 0.5$ and $\mathrm{NaCl}, 0.5$ (Varma \& Nene, 2003). Medium (5): soluble starch, 10; glucose, 10; peptone, 30; beef extract, $30 ; \mathrm{MgS0}_{4} \cdot 7 \mathrm{H}_{2} \mathrm{O}, 1$ and $\mathrm{NaCl}$, 7.5 (Kajiya et al., 1991). Medium (6): $\left(\mathrm{NH}_{4}\right)_{2} \mathrm{SO}_{4}, 2$; glycerol, 5; $\mathrm{K}_{2} \mathrm{HPO}_{4}, 2$; $\mathrm{MgSO}_{4} .7 \mathrm{H}_{2} \mathrm{O}, 0.2$ and peptone, 2 (Richmond, 1973) and cholesterol was added to each of the production media as $2 \mathrm{~g}$ in $1 \%$ Triton X100 per liter. Fifty $\mathrm{ml}$ at of each production medium at $\mathrm{pH} 7$ in $250 \mathrm{ml}$ Erlenmeyer flasks were inoculated and incubated in an orbital shaker at $32{ }^{\circ} \mathrm{C}$ and $200 \mathrm{rpm}$ for 5 days. The fermentation profile was studied by harvesting triplicate flasks at intervals of $24 \mathrm{~h}$. The supernatant of the fermented broth was used for protein determination and enzyme assay to select an appropriate basal medium for subsequent medium optimization.

\section{Medium optimization using the classical one-factor-at-a-time method}

Classical approaches, like removal, supplementation, and replacement experiments were performed using OFAT methodology for the selection of effective medium components for $\mathrm{CHO}$ production (Singh et al., 2017). Each component of the best-selected media was eliminated one-by-one and the other components were left in the production media to realize the importance of each component and to reveal its significance in the production of $\mathrm{CHO}$. The study was carried out in $250 \mathrm{ml}$ Erlenmeyer flasks containing $50 \mathrm{ml}$ of the selected medium at $\mathrm{pH} 7$ on a rotary shaker at $200 \mathrm{rpm}$ and $32^{\circ} \mathrm{C}$ for $120 \mathrm{hrs}$.

\section{Statistical medium optimization}

This design is extremely useful in finding the importance of the factors affecting the production of the enzyme. The independent variables which were chosen based on our preliminary experimental results using OFAT methodology were screened in Plackett-Burman design (PB) of 12 experiments. Four medium components and their ranges of concentrations were prepared at two levels -1 for low level and +1 for a high level. The actual values of the PB experimental design are based on the first order model as given in the following equation: $\mathrm{Y}=\beta_{0}+\sum \beta_{\mathrm{i}} \mathrm{X}_{\mathrm{i}}$ where $\mathrm{Y}$ is the response (enzyme activity), $\beta_{0}$ is the model intercept, $\beta_{\mathrm{i}}$ is the linear coefficient, and $\mathrm{X}_{\mathrm{i}}$ is the level of the independent variables (medium components). This model was applied to identify the significant variables that influence $\mathrm{CHO}$ production and the variables that have confidence levels higher than $95 \%$ were considered significant. All the experiments were performed in triplicate and the average of $\mathrm{CHO}$ activity was used as the response (dependent variable). The main effect of each variable was calculated as the difference between the averages of measurements made at the high value (+) and at the low value (-).

Central composite design (CCD) was used in the next step to determine the optimum levels of significant factors for the production of $\mathrm{CHO}$. The central composite design with two medium components at five levels $(-2,-1,0,+1,+2)$ for each factor resulting in a total of 13 experimental runs. Other media components were chosen at the low-level concentrations from the PB design $(P>0.05)$. The results of the CCD were expressed by the following second order polynomial using a multiple regression technique according to the following equation: $\mathrm{Y}=\beta_{0}+\beta_{\mathrm{i}} \mathrm{X}_{\mathrm{i}}+\beta_{\mathrm{ii}} \mathrm{X}_{\mathrm{i}}{ }^{2}+\beta_{\mathrm{ij}} \mathrm{X}_{\mathrm{i}} \mathrm{X}_{\mathrm{j}}$ where $\mathrm{Y}$ is the predicted value of $\mathrm{CHO}$ activity, $\beta_{0}, \beta_{\mathrm{i}}, \beta_{\mathrm{ii}}$, and $\beta_{\mathrm{ij}}$ represents the constant process effects in total, linear, quadratic and the interaction effect between $X_{i}$ and $X_{j}$ respectively for the production of $\mathrm{CHO}$ in which $\mathrm{X}_{\mathrm{i}}$ and $\mathrm{X}_{\mathrm{j}}$ are the coded independent variables. The second- order polynomial equation was used to calculate the relationship between the independent factors and the response. Later, an experiment was running using the optimum values for variables given by response optimization to confirm the predicted value of $\mathrm{CHO}$ maximum concentration.

\section{Statistical analysis and method validation}

All statistical/ mathematical analysis and their graphs were performed using Minitab 17.0 software and the three-dimensional (3D) response surface plots were obtained using Statistica 8 software.

\section{RESULTS AND DISCUSSION}

Optimization of cholesterol oxidase enzyme production by Streptomyces sp. strain NHIA_CH5

Streptomyces sp. is considered as a promising $\mathrm{CHO}$ producer that vary from strain to strain as stated in different reports: S. badius produced $2.45(\mathrm{U} / \mathrm{mL})$, S. fradiae, $3.14(\mathrm{U} / \mathrm{mL})$ and $S$. lavendulae, $2.21(\mathrm{U} / \mathrm{mL})$. Other Streptomyces like $S$. violascens and $S$. parvus are reported as $\mathrm{CHO}$ enzyme producers (Srivastava et al., 2018a). CHO production was significantly affected by the type of media (Figure 1a). Among the six production media, Streptomyces sp.strain NHIA_CH5 showed the highest CHO production $(23.7 \mathrm{U} / \mathrm{mL})$ when grown in medium 5, on the other hand, the lesser production of $\mathrm{CHO}$ (9.539 $\mathrm{U} / \mathrm{mL}$ ) was recorded when grown in medium (1). The results indicated that medium (5) enhanced the production of $\mathrm{CHO}$ by Streptomyces sp. strain NHIA_CH5 that reached a maximum value at incubation time 96 hours as compared to other media used. This may be attributed to the presence of the essential nutrients that meet the demand of the cells to produce the enzyme. It contains beef extract $30 \mathrm{~g} / \mathrm{L}$ and peptone $30 \mathrm{~g} / \mathrm{L}$ distinctive from the other nutrients media components under study. Previous report demonstrated that various compounds, such as yeast extract, glycerol, malt extract, soybean meal, potato starch, and peptone are substrates in cholesterol-based media for the optimization production of $\mathrm{CHO}$ as described by Ahmad \& Goswami, (2012) during improvement of enzyme production by the statistical method from Rhodococcus sp. NCIM 2891 recorded 9.7-fold higher in the enzymatic activity than result obtained before optimization. Also, the specific activities are influenced by the medium composition recorded the highest value of $28 \mathrm{U} / \mathrm{mg}$ protein in medium (5) at 96 hours (Figure 1b). Hence, medium (5) was selected for further studies due to its relatively high enhancement of extracellular $\mathrm{CHO}$ produced by Streptomyces sp.strain NHIA_CH5. Earlier study reported that glycerol and the soybean meal supports $\mathrm{CHO}$ production by S. lavendulae (Pathak et al., 2015)

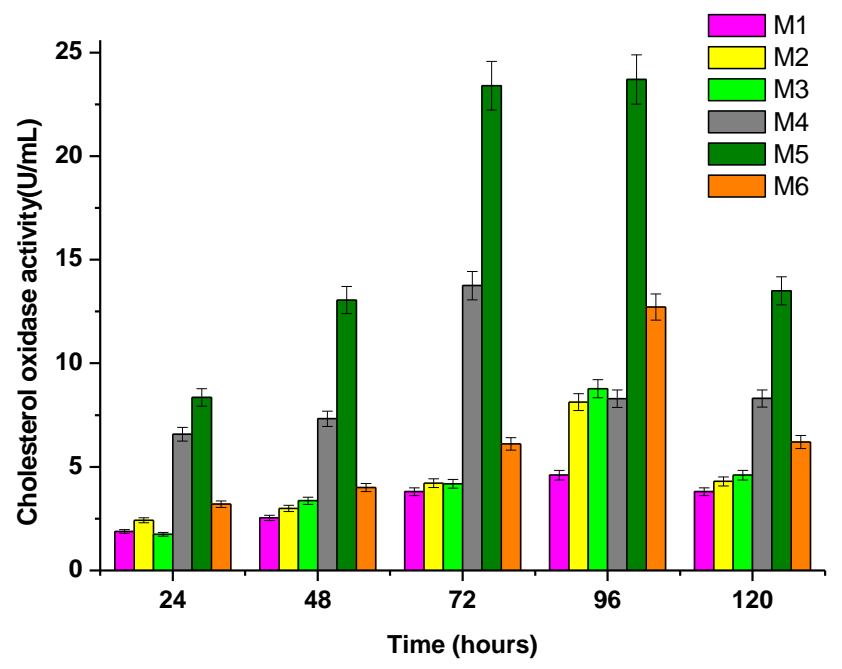




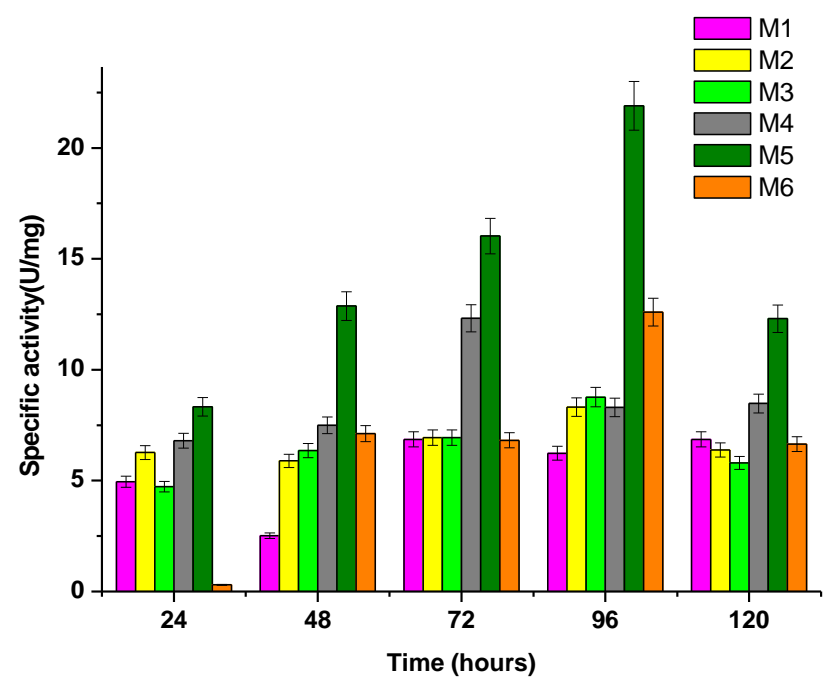

b

Figure 1 CHO activity profile by Streptomyces sp. strain NHIA_CH5 grown in six different media, b) CHO specific activities profile. All the data were obtained from triplicate experiments (mean $\pm \mathrm{SD}$ ).

\section{Medium optimization using the classical OFAT method}

The constituents of medium (5) were eliminated one by one in order to identify the importance of each component in the production of CHO by Streptomyces sp. strain NHIA_CH5 using the whole medium as a control (Figure 2). The results demonstrated that the elimination of soluble starch (medium 2), peptone (medium 1), glucose (medium 6) and beef extract (medium 4) decreased the production by almost $3.7,10,22$ and $67 \%$ respectively, while the elimination of $\mathrm{NaCl}$ (medium 5) and $\mathrm{MgSO}_{4} \cdot 7 \mathrm{H}_{2} \mathrm{O}$ (medium 3) increased the production by almost 4 and $6 \%$. These findings were in accordance with those described by Srivastava $\boldsymbol{e t}$ al., (2018a) who reported that elimination of glucose and yeast extract from the production medium decreased the productivity of $\mathrm{CHO}$ by 20 and $30 \%$, respectively during the cultivation of S. rimosus MTCC 10792. From our results, we concluded that further optimization with response surface methodology requested the necessary components for $\mathrm{CHO}$ enzyme production including soluble starch, glucose, peptone, and beef extract. Earlier, these components were considered as growth-promoting substances for production of many enzymes (Al-Dhabi $\boldsymbol{e t} \boldsymbol{a l}, \mathbf{2 0 2 0})$. Metal ions are generally not required for cholesterol oxidase activity (Doukyu, 2009), however, Pathak et al., (2015) demonstrated that $\mathrm{MgSO}_{4}$ was found to be more influential than $\mathrm{NaCl}$ for $\mathrm{CHO}$ activity during the experiments on Streptomyces sp. NCIM 5500, in contrast with the previous report of Amiri et al., (2008), who notified that $\mathrm{NaCl}$ supported $\mathrm{CHO}$ production than $\mathrm{MgSO}_{4}$. However, other reports by other researchers favored the use of both salts in the production medium (Chauhan et al., 2009).

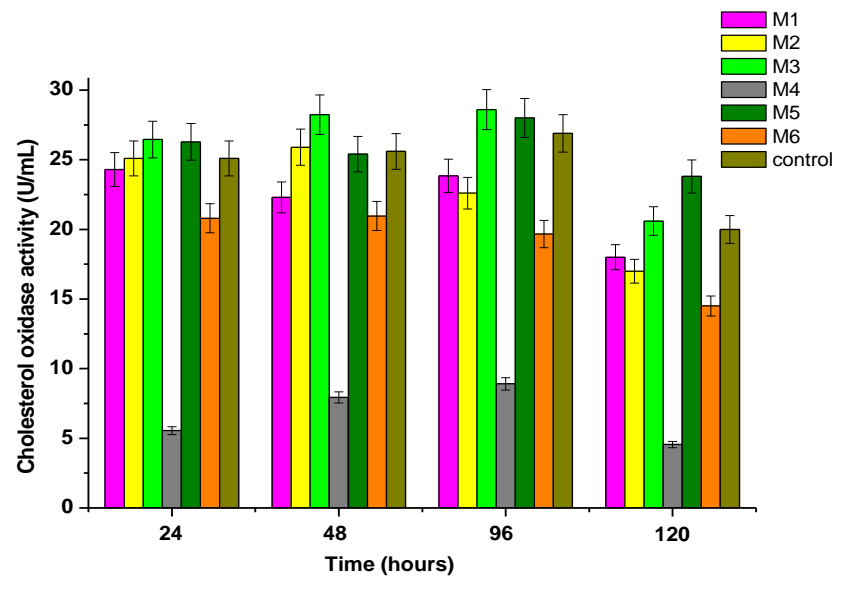

a)

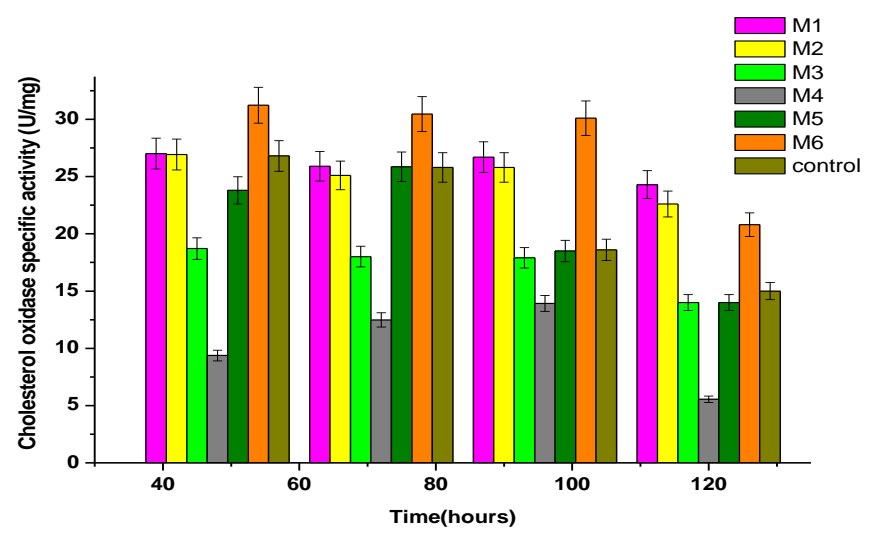

b)

Figure 2 a) CHO activity profile by Streptomyces sp. strain NHIA_CH5 grown in six different media using a classical one-factor-at-a-time method: medium 1 (without peptone only); medium 2 (without soluble starch only); medium 3 (without $\mathrm{MgSO}_{4} .7 \mathrm{H}_{2} \mathrm{O}$ only); medium 4 (without beef extract only); medium 5 (without $\mathrm{NaCl}$ only) and medium 6 (without glucose only) compared with the control medium containing all components, b) The specific activity profiles of $\mathrm{CHO}$. All the data were from triplicate experiments (mean $\pm \mathrm{SD}$ ).

\section{Optimization of production medium by PBD}

Based on the results obtained from OFAT method, the importance of the four components including soluble starch, glucose, peptone, and beef extract for $\mathrm{CHO}$ production was investigated by PBD, a statistical method used to select efficiently the levels of the most influential factors on the production process by few experimental runs. In this study, the design matrix along with the observed response (CHO production) was presented in Table 1 . The results revealed a variation ranged from 29.8 to $41.13(\mathrm{U} / \mathrm{mL})$ reflecting the significant effect of the medium nutrients components participated in the production of CHO enzyme. The highest $\mathrm{CHO}$ production was found in the run (8). This could be related to the presence of peptone and beef extract in high concentration level while run (3) showed the lowest $\mathrm{CHO}$ production despite the presence of glucose and peptone at a high level, this may be due to the existence of soluble starch and beef extract in a low concentration level because they were consumed by Streptomyces sp. strain NHIA_CH5 after the action of maximum cell growth formation. Generally, due to the availability of enough nutrients, a higher concentration of primary metabolites is achieved in exponential phase as described during the production of $\alpha$-amylase from thermophilic bacterial strain Bacillus sp. BCC 01-50 (Simair et al., 2017). 
Table 1 The factors and their levels employed in the PBD for CHO production by Streptomyces sp. strain NHIA_CH5 (values in the parenthesis indicate the level)

\begin{tabular}{lccccc}
\hline Runs & Soluble starch $(\mathrm{g} / \mathrm{L})$ & Glucose $(\mathrm{g} / \mathrm{L})$ & Peptone $(\mathrm{g} / \mathrm{L})$ & Beef extract $(\mathrm{g} / \mathrm{L})$ & $\begin{array}{c}\text { CHO activity }(\mathrm{U} / \mathrm{mL}) \pm \\
\text { standard error }\end{array}$ \\
\hline $\mathbf{1}$ & $30(+1)$ & $20(-1)$ & $45(+1)$ & $35(-1)$ & $32.33 \pm 1.6165$ \\
\hline $\mathbf{2}$ & $30(+1)$ & $30(+1)$ & $35(-1)$ & $45(+1)$ & $37.980 \pm 1.899$ \\
\hline $\mathbf{3}$ & $20(-1)$ & $30(+1)$ & $45(+1)$ & $35(-1)$ & $29.800 \pm 1.49$ \\
\hline $\mathbf{4}$ & $30(+1)$ & $20(-1)$ & $45(+1)$ & $45(+1)$ & $30.880 \pm 2.044$ \\
\hline $\mathbf{5}$ & $30(+1)$ & $30(+1)$ & $35(-1)$ & $45(+1)$ & $32.980 \pm 1.899$ \\
\hline $\mathbf{6}$ & $30(+1)$ & $30(+1)$ & $45(+1)$ & $35(-1)$ & $39.300 \pm 1.6075$ \\
\hline $\mathbf{7}$ & $20(-1)$ & $30(+1)$ & $45(+1)$ & $45(+1)$ & $41.130 \pm 2.0565$ \\
\hline $\mathbf{8}$ & $20(-1)$ & $20(-1)$ & $45(+1)$ & $45(+1)$ & $39.212 \pm 1.9606$ \\
\hline $\mathbf{9}$ & $20(-1)$ & $20(-1)$ & $35(-1)$ & $45(+1)$ & $33.160 \pm 1.658$ \\
\hline $\mathbf{1 0}$ & $30(+1)$ & $20(-1)$ & $35(-1)$ & $35(-1)$ & $33.160 \pm 1.658$ \\
\hline $\mathbf{1 1}$ & $20(-1)$ & $30(+1)$ & $35(-1)$ & $35(-1)$ & $35.294 \pm 1.7647$ \\
\hline $\mathbf{1 2}$ & $20(-1)$ & $20(-1)$ & $35(-1)$ & & $35(-1)$ \\
\hline
\end{tabular}

Analysis of variance (ANOVA) is an inferential method used to test the statistical significance of the model using Fisher's F-test and its associated probability $\mathrm{P}(\mathrm{F})$. The ANOVA result for significant medium components is demonstrated in Table 2. The P-value of the model was lower than 0.05 ( $\mathrm{P}<$ 0.05 ) indicating that the model is statistically valid. The results of PBD revealed that beef extract $(\mathrm{P}-$ Value $=0.000 ; \mathrm{F}$-Value $=74.66)$, glucose $(\mathrm{P}-$ Value $=0.042$ F-Value $=6.14)$ had $(\mathrm{P}<0.05)$ and high F-values evidenced their potential impact on $\mathrm{CHO}$ activity consequently these factors were selected for further optimization by response surface methodology (RSM). Because soluble starch and peptone did not have significant effects on $\mathrm{CHO}$ production, they were added in the cultivation medium at their median values for subsequent experiments. The quality of the polynomial model equation was judged statistically by the coefficient of determination $\left(\mathrm{R}^{2}\right)$ which provides an indicator for the variability of the predicted response ( $\mathrm{CHO}$ production) and the experimental data and the adjusted $R^{2}$. The coefficients of determination are high $\left(R^{2}=92.08 \%\right.$ and adjusted
$\mathrm{R}^{2}=87.56 \%$ ) indicated that the data variability could be fully explained by the model. Based on our ANOVA results, a first-order polynomial equation (equation 1) was derived, which represented the $\mathrm{CHO}$ activity as an equation of four independent variables as follows:

CHO activity $(\mathrm{U} / \mathrm{mL})=16.04-0.0569$ starch $(\mathrm{g} / \mathrm{L})-0.1939$ glucose $(\mathrm{g} / \mathrm{L})$ 0.0199 peptone $\quad(\mathrm{g} / \mathrm{L}) \quad+0.6765$ beef $\quad(\mathrm{g} / \mathrm{L})$ The regression equation used to predict the values of the dependent variable (CHO production) from the given values of independent variables (starch, glucose, peptone and beef extract) reveals that beef extract has the largest coefficient that is preceded by a positive sign, indicated its strong enhancement effect on $\mathrm{CHO}$ production in the high level of beef extract concentration whereas glucose coefficient in negative sign recommended the increase of $\mathrm{CHO}$ production with low level of glucose concentration .

Table 2 Analysis of Variance (ANOVA) for a linear model on the effect of independent variables on CHO production

\begin{tabular}{|c|c|c|c|c|c|}
\hline Source & DF & Adj SS & Adj MSS & F-Value & P-Value \\
\hline Model & 4 & 149.657 & 37.414 & 20.35 & 0.001 \\
\hline Soluble starch $(\mathrm{g} / \mathrm{L})$ & 1 & 0.972 & 0.972 & 0.53 & 0.491 \\
\hline Glucose $(\mathrm{g} / \mathrm{L})$ & 1 & 11.283 & 11.283 & 6.14 & 0.042 \\
\hline Peptone (g/L) & 1 & 0.119 & 0.119 & 0.06 & 0.806 \\
\hline Beef extract $(\mathrm{g} / \mathrm{L})$ & 1 & 137.282 & 137.282 & 74.66 & 0.000 \\
\hline Error & 7 & 12.871 & 1.839 & & \\
\hline Total & 11 & 162.528 & & & \\
\hline \multicolumn{6}{|l|}{ Model summary } \\
\hline & $\mathbf{S}$ & R-sq & R-sq (adj.) & R-sq (pred.) & \\
\hline & 1.35602 & $92.08 \%$ & $87.56 \%$ & $76.73 \%$ & \\
\hline
\end{tabular}

DF: Degree of freedom; Adj. SS: Adjusted sum of squares; Adj. MSS: Adjusted Mean sum of squares (are adjusted sums of squares (Adj. SS) divided by the corresponding DF); F: Fishers's function; P: corresponding level of significance.

The main effect is the effect of one of the medium constituent on $\mathrm{CHO}$ production ignoring the effects of all other constituents characterize the deviation of the average between high and low levels for each one of the factors. The greater the deviation from the parallel (x-axis), the greater is the influence of the component on $\mathrm{CHO}$ production as indicated by the graph of Figure 3 , as indicated with beef extract followed by glucose. The experimental data revealed that the selected low-level values of starch $20 \mathrm{~g} / \mathrm{L}$, glucose $20 \mathrm{~g} / \mathrm{L}$ and peptone 35 $\mathrm{g} / \mathrm{L}$ represented by their plots in negative direction and the high-level values of beef extract $45 \mathrm{~g} / \mathrm{L}$ represented by its plot in positive direction were preferable for $\mathrm{CHO}$ production in the selected media.

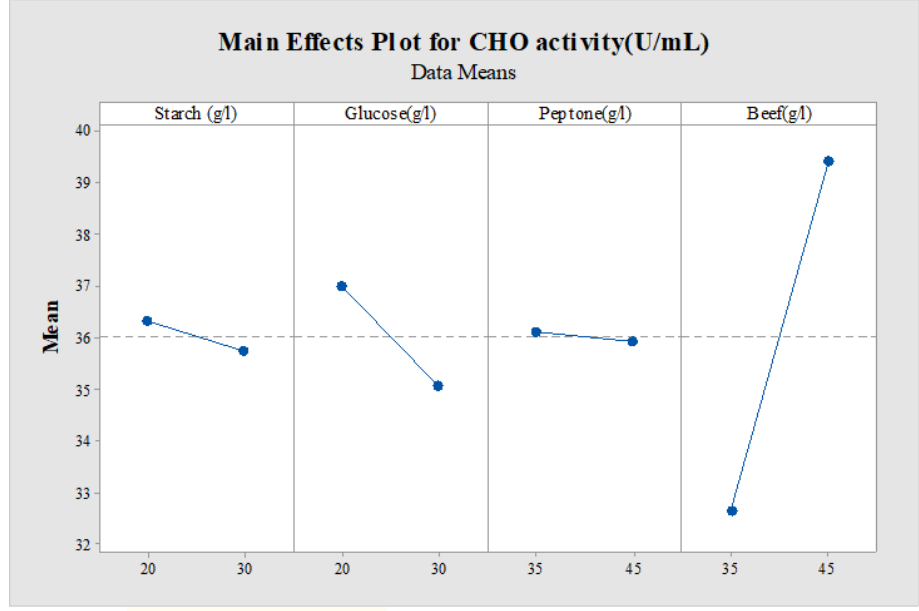

Figure 3 Main effects plots of medium components (independent factors) for $\mathrm{CHO}$ production based on Plackett-Burman design results in which $\mathrm{X}$-axis represents assigned levels of the selected factor and $\mathrm{Y}$-axis represents $\mathrm{CHO}$ activity $(\mathrm{U} / \mathrm{mL})$ 
Based on PBD results, the most important effects of the factors on the response (CHO production) were obviously illustrated in decreasing order by the Pareto chart. The statistically most significant factors beef extract and glucose indicated by their long columns are crossed by a line corresponding to 2.365 of $t$-value at 95\% confidence level, confirmed their large influence on the production while other factors soluble starch and peptone are not significant (Figure 4).

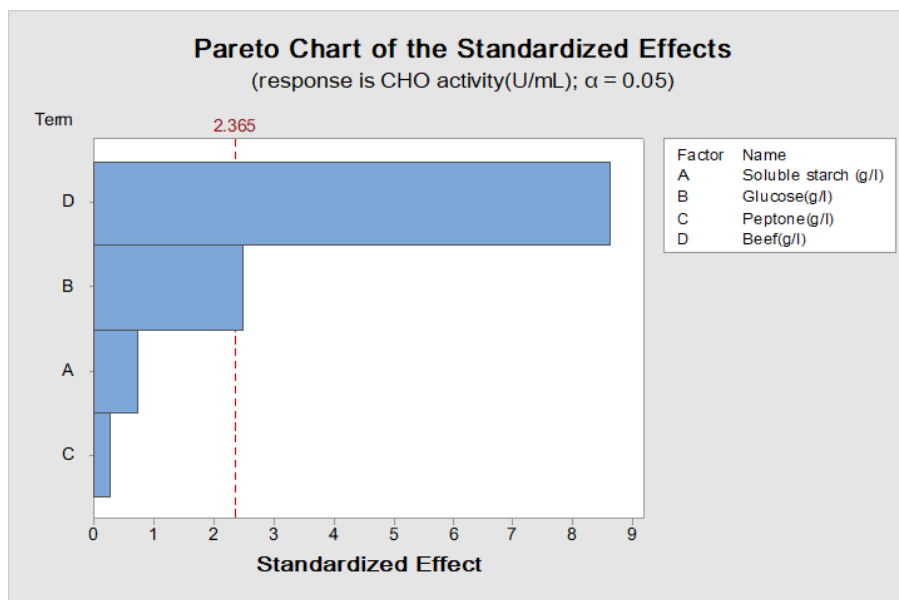

Figure 4 Pareto chart showing the effect of different media component (variables) on $\mathrm{CHO}$ production based on the observations of Plackett-Burman design. The point at which the effects estimates were statistically significant (at $\mathrm{P}$ $=0.05$ ) indicated by the vertical line.

Plackett-Burman design was used for the identification of the most effective critical nutrient components that affecting the enzyme production but it does not examine the interactive effects between the selected components which were further studied by employing central composite design (CCD) of RSM By neglecting the terms that were insignificant $(\mathrm{P}>0.05)$, beef extract and glucose were selected as the most influencing variables that were subjected to further optimization using CCD. The CCD experimental matrix with the actual and the coded values of the selected parameters is given in Table 3 .
Table 3 Central composite design matrix with two independent variables and their actual and coded (in parenthesis) levels; showing observed responses for the production of

\begin{tabular}{lccc}
\hline Runs & $\begin{array}{c}\text { Beef extract } \\
(\mathbf{g} / \mathbf{L})\end{array}$ & $\begin{array}{c}\text { Glucose } \\
(\mathbf{g} / \mathbf{L})\end{array}$ & $\begin{array}{c}\text { CHO activity }(\mathbf{U} / \mathbf{m L}) \pm \text { standard } \\
\text { error }\end{array}$ \\
\hline $\mathbf{1}$ & $40(-1)$ & $25(-1)$ & $34.54 \pm 1.727$ \\
\hline $\mathbf{2}$ & $50(+1)$ & $25(-1)$ & $35.43 \pm 1.7715$ \\
\hline $\mathbf{3}$ & $40(-1)$ & $35(+1)$ & $34.90 \pm 1.745$ \\
\hline $\mathbf{4}$ & $50(+1)$ & $35(+1)$ & $39.45 \pm 1.9725$ \\
\hline $\mathbf{5}$ & $35(-2)$ & $30(0)$ & $29.85 \pm 1.4925$ \\
\hline $\mathbf{6}$ & $55(+2)$ & $30(0)$ & $40.06 \pm 2.003$ \\
\hline $\mathbf{7}$ & $45(0)$ & $20(-2)$ & $35.15 \pm 1.7575$ \\
\hline $\mathbf{8}$ & $45(0)$ & $40(+2)$ & $40.08 \pm 2.004$ \\
\hline $\mathbf{9}$ & $45(0)$ & $30(0)$ & $31.44 \pm 1.572$ \\
\hline $\mathbf{1 0}$ & $45(0)$ & $30(0)$ & $31.44 \pm 1.572$ \\
\hline $\mathbf{1 1}$ & $45(0)$ & $30(0)$ & $32.10 \pm 1.605$ \\
\hline $\mathbf{1 2}$ & $45(0)$ & $30(0)$ & $30.50 \pm 1.525$ \\
\hline & $45(0)$ & $30(0)$ & $31.50 \pm 1.575$ \\
\hline
\end{tabular}

As it is evident from the calculated $\mathrm{F}$ value (F model=10.31) and the very low probability value $(\mathrm{P}$ model $=0.004)$ lower than 0.05 , the ANOVA of the regression model demonstrates that the model is highly significant (Table 4). The regression coefficient of each variable in terms of linear, quadratic and interaction, along with $\mathrm{p}$-values at $95 \%$ confidence was observed from ANOVA study. The linear effect of beef extract $(\mathrm{P}=0.039)$ and glucose $(\mathrm{P}=0.018)$ indicating their importance in the enzyme outcome whereas the quadratic effect of beef extract $(\mathrm{P}=0.031)$ and glucose $(\mathrm{P}=0.002)$ were found to be significant $(\mathrm{P}<0.05)$ indicating that the treatment with concentrations higher than the optimum values increased the $\mathrm{CHO}$ production. Also, the determination coefficient $\left(\mathrm{R}^{2}\right)$ indicated that the second order polynomial model (equation 2) fits to the experimental data and can explain $88.04 \%$ of the variations in the result and only about $11.96 \%$ of the tota variations are not explained by the model. Also, the adjusted determination coefficient ( $\mathrm{R}^{2}$ adj) was $79.50 \%$, corrects the $\mathrm{R}^{2}$ value for the sample size and the number of terms in the model.

Table 4 Analysis of variance values for the quadratic regression model obtained from central composite for the CHO production

\begin{tabular}{|c|c|c|c|c|c|}
\hline Analysis of variance & & & & & \\
\hline Source & DF & Adj SS & Adj MSS & F-Value & P-Value \\
\hline Model & 5 & 139.794 & 27.9587 & 10.31 & 0.004 \\
\hline Linear & 2 & 27.008 & 13.5040 & 4.98 & 0.045 \\
\hline Beef $(g / L)$ & 1 & 17.302 & 17.3025 & 6.38 & 0.039 \\
\hline Glucose $(g / L)$ & 1 & 25.727 & 25.7271 & 9.48 & 0.018 \\
\hline Square & 2 & 63.818 & 31.9091 & 11.76 & 0.006 \\
\hline Beef $(g / L) *$ Beef $(g / L)$ & 1 & 19.748 & 19.7482 & 7.28 & 0.031 \\
\hline $\operatorname{Glucose}(\mathrm{g} / \mathrm{L}) * \operatorname{Glucose}(\mathrm{g} / \mathrm{L})$ & 1 & 58.173 & 58.1731 & 21.44 & 0.002 \\
\hline 2-Way Interaction & 1 & 3.349 & 3.3489 & 1.23 & 0.303 \\
\hline Beef $(g / L) *$ Glucose $(g / L)$ & 1 & 3.349 & 3.3489 & 1.23 & 0.303 \\
\hline Error & 7 & 18.99 & 2.7130 & & \\
\hline Lack-of-Fit & 3 & 17.678 & 5.8927 & 17.95 & 0.009 \\
\hline Pure Error & 4 & 1.313 & 0.3283 & & \\
\hline Total & 11 & 162.5 & & & \\
\hline \multicolumn{6}{|l|}{ Model Summary } \\
\hline & $\mathbf{S}$ & R-sq & R-sq (adj.) & R-sq (pred.) & \\
\hline & 1.64713 & $88.04 \%$ & $79.50 \%$ & $14.76 \%$ & \\
\hline
\end{tabular}

DF: Degree of freedom; Adj. SS: Adjusted sum of squares; Adj. MSS: Adjusted Mean sum of squares (are adjusted sums of squares (Adj. SS) divided by the corresponding DF); F: Fishers's function; P: corresponding level of significance.

For predicting the optimal values of the components within the experimental results, multiple regression analysis of the experimental data for $\mathrm{CHO}$ production gave the following second-order polynomial equation (equation 2):

$\mathrm{CHO}$ activity $(\mathrm{U} / \mathrm{mL})=187.5-4.01$ beef $(\mathrm{g} / \mathrm{L})-5.23$ glucose $(\mathrm{g} / \mathrm{L})$ +0.0371 beef $\quad(\mathrm{g} / \mathrm{L}) *$ beef $\quad(\mathrm{g} / \mathrm{L}) \quad+0.0637$ glucose $\quad(\mathrm{g} / \mathrm{L}) * \mathrm{glucose} \quad(\mathrm{g} / \mathrm{L})$ +0.0366 beef $(\mathrm{g} / \mathrm{L})^{*}$ glucose $(\mathrm{g} / \mathrm{L})$.

The regression equation is graphically represented by the $2 \mathrm{D}$ contour plot to visualize the effect of beef extract and glucose concentration on $\mathrm{CHO}$ production. Each ellipse in the $2 \mathrm{D}$ contour plot represents one response value (CHO concentration) affected interactively by the two variables (beef extract and glucose). The optimal values of the variables could be obtained in the smallest ellipse (dark green area above right in the graph). From the contour plot, it is evident that the interaction of beef extract and glucose was elliptical in shape, indicating that the effects of the interaction of the two factors are significant and a high concentration of them was necessary for high $\mathrm{CHO}$ production (Figure 5). Also the 3-Dimensional (3D) RSM plots clearly indicated that the maximum CHO production should occur with high levels of glucose and beef extract as represented by the dark red area in the surface plot (Figure 6). 
Contour Plot of $\mathrm{CHO}$ activity $(\mathrm{U} / \mathrm{mL})$ vs Glucose(g/l); Beef(g/l)

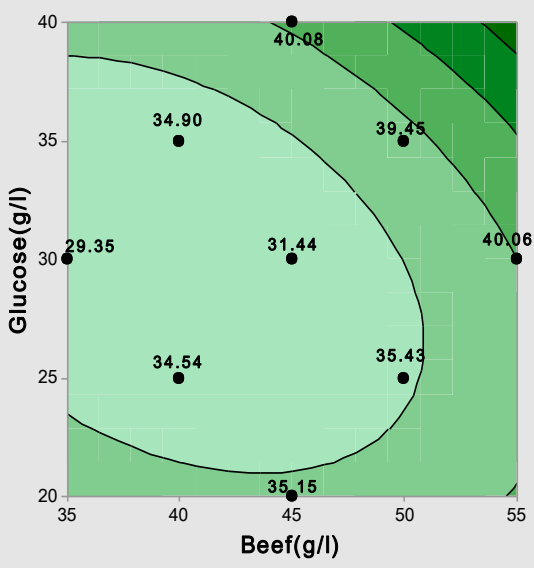

Figure 5 Contour plot represents the effect of beef extract and glucose on $\mathrm{CHO}$ production

3D Surface Plot of $\mathrm{CHO}$ activity $(\mathrm{U} / \mathrm{mL})$ against beef extract $(g / L)$ and glucose(g/L)
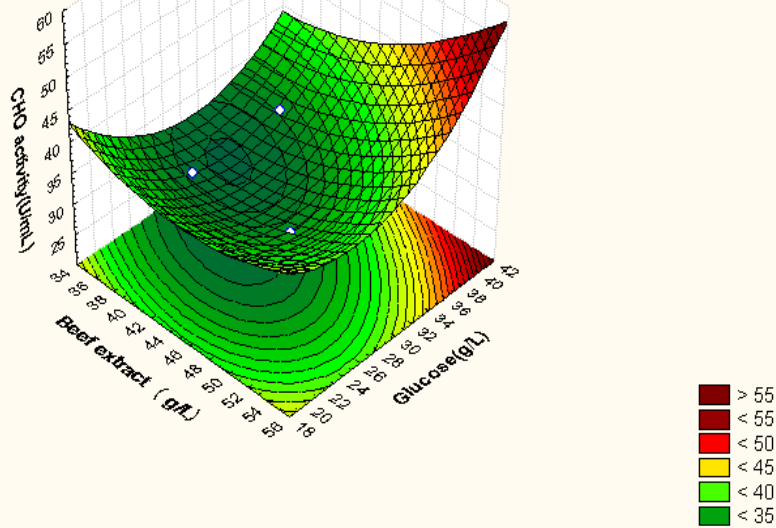

Figure 6 Response surface plot (3D) showing the interactive effects of variables on $\mathrm{CHO}$ production by Streptomyces sp. strain NHIA_CH5

\section{Validation of the optimized medium components}

In order to verify the optimization results, experiments under optimized culture conditions for maximizing $\mathrm{CHO}$ production, each individual variable estimated previously through regression model and its quantitative amount was predicted and transformed into a desirability value (Figure 7). Response optimization method identifies the combination of input variable settings that optimize a single response (CHO production) expressed by a single desirability index, D. When D was close to 1 indicating the fact that the function increases linearly towards the desired target values to maximize CHO production (Abdelwahed et al., 2017) The solid line of beef extract and glucose revealed that as their values increase, the production of $\mathrm{CHO}$ will increase. The predicted concentrations of beef extract and glucose in the recommended optimal model parametric settings of maximum $\mathrm{CHO}$ production were $55 \mathrm{~g} / \mathrm{L}$ and $40 \mathrm{~g} / \mathrm{L}$, respectively . The $\mathrm{CHO}$ enzyme activity using these values with the desirability of 1.0000 was $52.44 \mathrm{U} / \mathrm{mL}$. Therefore, the predicted optimum condition was verified experimentally recorded $50.5 \mathrm{U} / \mathrm{m}$ revealed more than $90 \%$ accuracy to the predicted response value, indicating the model validation under the tested conditions. Finally, the production medium for maximum $\mathrm{CHO}$ production was as follow $(\mathrm{g} / \mathrm{L})$ : soluble starch, 20; glucose, 40 peptone, 35 and beef extract, 55 . In our study, the $\mathrm{CHO}$ production resulted from the un-optimized medium was $23.7 \mathrm{U} / \mathrm{mL}$ and it was significantly increased to $50.5 \mathrm{U} / \mathrm{mL}$ realized almost 2 - fold increase in the production. Previously, various statistical techniques have been successfully applied for the optimization of $\mathrm{CHO}$ production by Streptomyces. In this research, the produced $\mathrm{CHO}$ activity was higher than that reported during cultivation of S. lavendulae by 2.48 fold (Chauhan et al., 2009). Also, it was higher than the activity recorded $5.41 \mathrm{U} / \mathrm{mL}$ reported by Srivastava et al., $(\mathbf{2 0 1 8 b})$ using S. rimosus.

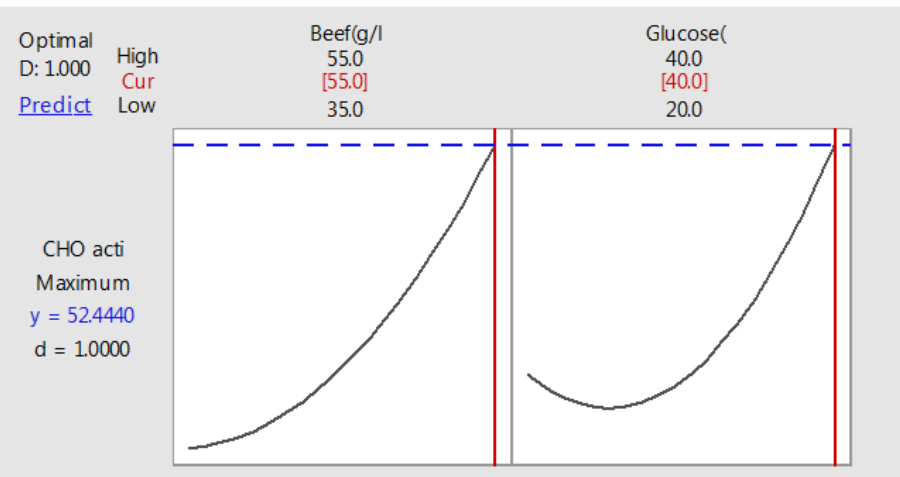

Figure 7 Optimization plot for $\mathrm{CHO}$

\section{CONCLUSION}

Streptomyces sp. strain NHIA_CH5 which is capable of producing cholesterol oxidase might be considered as the potentially interesting source of $\mathrm{CHO}$ for commercial and medicinal purposes. The optimized medium for maximum production was studied and finally determined by the statistical method. Optimization was confirmed by the desirability parameter, which attained a value considered good and acceptable by literature. We are in current to apply this optimized medium in large scale production to approach the semi-industrial scale for bioprocess strategies applications for $\mathrm{CHO}$ enzyme production.

Acknowledgments: The authors are grateful to the authorities of National Research Centre, Dokki, Giza, Egypt, for providing laboratory facilities and funding this work (project No. 11090302) to carry out this study.

\section{REFERENCES}

Abdelwahed, N.A.M., Ahmed, E.F., El-Gammal, E.W. \& Hawas, U.W. (2014) Application of statistical design for the optimization of dextranase production by a novel fungus isolated from Red Sea sponge. 3 Biotech. 4, 533-544. https://doi.org/10.1007/s13205-013-0187-4

Abdelwahed, N.A.M., Gomaa, E.Z. \& Hassan, A.A. (2017). Statistical Modelling and Optimization of Fermentation Medium for Lincomycin Production by Streptomyces lincolnensis Immobilized Cells. Brazilian Archives of Biology and Technology, 60, 1-14. https://doi.org/10.1590/1678-4324$\underline{2017160210}$

Ahmad, S., Goswami, P. (2012). Enhanced production of cell-bound cholesterol oxidase from Rhodococcus sp. NCIM 2891 by the statistical method. Annals of Microbiology, 63, 199-205. https://doi.org/10.1007/s13213-012-0461-4

Al-Dhabi, N. A., Esmail, G. A., Ghilan, A. M., \& Arasu, M. V. (2020). Isolation and screening of Streptomyces sp. Al-Dhabi-49 from the environment of Saudi Arabia with concomitant production of lipase and protease in submerged fermentation. Saudi journal of biological sciences, 27(1), 474-479. https://doi.org/10.1016/j.sjbs.2019.11.011

Alshehri, W. A. (2020). Bacterium Hafnia alvei secretes 1-methioninase enzyme: Optimization of the enzyme secretion conditions Saudi Journal of Biological Sciences, 27, 1222- 1227. https://doi.org/10.1016/j.sjbs.2020.02.008 Allain, C.C., Poon, L.S., Chan, C.S.G., Richmond, W., Fu, P.C. (1974) Enzymatic determination of total serum cholesterol. Clinical Chemistry, 20 470-475.

Amiri, M., Najafi, A.A. \& Gheshlaghi, K. (2008). Response surface methodology and genetic algorithm in optimization of cement clinkering process. Applied Sciences, 8, 2732-2738. https://doi.org/10.3923/jas.2008.2732.2738

Brzostek, A., Dziadek, B., Rumijowska-Galewicz, A., Pawelczyk, J. \& Dziadek, J. (2007). Cholesterol oxidase is required for virulence of Mycobacterium tuberculosis. FEMS Microbiology Letters, 275, 106-112. https://doi.org/10.1111/j.1574-6968.2007.00865.x

Chauhan, A.K., Survase, S.A., Kishenkumar, J. \& Annapure, U.S. (2009) Medium optimization by orthogonal array and response surface methodology for cholesterol oxidase production by Streptomyces lavendulae NCIM 2499 Journal of General and Applied Microbiology, 55, 171-180. https://doi.org/10.2323/jgam.55.171

Devi, S., Kanwar, S.S. (2017). Cholesterol oxidase: source, properties and applications. Insights in Enzyme Research, 1, 1-5. Doukyu, N. (2009). Characteristics and biotechnological applications of microbial cholesterol oxidases. Applied Microbiology and Biotechnology $\quad \mathbf{8 3}, 825$ 837. https://doi.org/10.1007/s00253-009-2059-8

Elsayed, A.E. \& Abdelwahed , N.A. (2020). Medium optimization by response surface methodology for improved cholesterol oxidase a newly isolated Streptomyces rochei NAM-19 Strain. BioMed Research International, 2020, 1-13. https://doi.org/10.1155/2020/1870807 
Ghosh, S., Ahmad, R \& Khare, S.K. (2018). Immobilization of Cholesterol Oxidase: An Overview. The Open Biotechnology Journal, 12, 176-188. https://doi.org/10.2174/1874070701812010176

Hashem, A.M., Gamal, A.A., Mansour, N.M., Salama, B.M., Hassanein, N.M., Awad, G.E.A. \&Esawy, M.A. (2018). Optimization of Enterococcus faecalis Esawy KR758759 dextransucrase and evaluation of some dextran bioactivities. Biocatalysis and Agricultural Biotechnology, $\quad 15, \quad 348-358$ https://doi.org/10.1016/j.bcab.2018.06.008

Kajiya, Y., Tsuda, R. \& Yoneyama, H. (1991). Conferment of cholesterol sensitivity on polypyrrole films by immobilization of cholesterol oxidase and ferrocenecarboxylate ions. Journal of Electroanalytical Chemistry and Interfacial Electrochemistry, 301, 155-164.https://doi.org/10.1016/0022-0728(91)85466-3

Khan, R., Solanki, P.R., Kaushik, A.K., Singh, S.P., Ahmad, S. \& Malhotra, B.D (2009). Cholesterol biosensor based on electrochemically prepared polyaniline conducting polymer film in presence of a nonionic surfactant. Journal of Polymer Research, 16, 363-373.https://doi.org/10.1007/s10965-008-9237-8

Lin, J., Lin, Y.S., Kuo, S.T., Jiang, C.M. \& Wu, M.C. (2009). Purification of soybean amylase by superparamagnetic particles. Food Chemistry, 117, 94-98. https://doi.org/10.1016/j.foodchem.2009.03.089

Lowry, O.H., Rosebrough, N.J., Farr, A.L. \& Randall, R.J. (1951). Protein measurement with the Folin phenol reagent. Journal of Biological Chemistry, $193,265-275$.

Mukhtar, S., Zaheer, A., Aiysha, D., Malik, K.A. \& Mehnaz, S. (2017). Actinomycetes: A Source of Industrially Important Enzymes. Journal of Proteomics \& Bioinformatics, 10, 316-319. https://doi.org/10.4172/jpb.1000456 Niwas, R., Singh, V., Singh, R., Tripathi, D. \& Tripath, C.K.M. (2013). Production, purification and characterization of cholesterol oxidase from a newly isolated Streptomyces sp. World Journal of Microbiology and Biotechnology, 29, 2077-2085.https://doi.org/10.1007/s11274-013-1371-8

Pathak, L., Singh, V., Niwas, R., Osama, K., Khan, S., Haque, S., Tripathi, C.K.M. \& Mishra, B.N. (2015). Artificial Intelligence versus Statistical Modeling and Optimization of Cholesterol Oxidase Production by using Streptomyces Sp. PLOS ONE, 10, e0137268.https://doi.org/10.1371/journal.pone.0137268

Rajeswari, P., Jose, P. A., Amiya, R., \& Jebakumar, S. R. (2015) Characterization of saltern based Streptomyces sp. and statistical media optimization for its improved antibacterial activity. Frontiers in Microbiology, 5,753. https://doi.org/10.3389/fmicb.2014.00753

Richmond, W. (1973). Preparation and properties of a cholesterol oxidase from Nocardia sp. and its application to the enzymatic assay of cholesterol in serum. Clinical Chemistry, 19, 1350-1356.

Sakkas, V.A., Islam, M.A., Stalikas, C. \& Albanis, T.A. (2010). Photocatalytic degradation using design of experiments: A review and example of the Congo red degradation. Journal of Hazardous Materials, 175, 33-44. https://doi.org/10.1016/j.jhazmat.2009.10.050

Simair, A. A., Qureshi, A. S., Khushk, I., Ali, C. H., Lashari, S., Bhutto, M. A., Mangrio, G. S., \& Lu, C. (2017). Production and Partial Characterization of $\alpha$ Amylase Enzyme from Bacillus sp. BCC 01-50 and Potential Applications. BioMed research international, 2017, 9173040. https://doi.org/10.1155/2017/9173040

Singh, S.K., Singh, S.K., Tripathi, V.R., Khare, S.K. \& Garg, S.K. (2011) Comparative one-factor-at-a-time, response surface (statistical and bench-scale bioreactor level optimization of thermoalkaline protease production from a psychrotrophic Pseudomonas putida SKG-1 isolate. Microbial Cell Factories ,10, 114-126. https://doi.org/10.1186/1475-2859-10-114

Singh, V., Haque, S., Niwas, R., Srivastava, A., Pasupuleti, M., Tripathi, C.K. (2017). Strategies for Fermentation Medium Optimization: An In-Depth Review. Frontiers in Microbiology, 7, 2087. https://doi.org/10.3389/fmicb.2016.02087

Srivastava, A., Singh, V. \& Tripathi, C.K.M. (2018a). Scale up and optimization of cholesterol oxidase production from Streptomyces rimosus MTCC 10792 in a 3-L bioreactor. Environmental and Sustainability, 1, 99107. https://doi.org/10.1007/s42398-018-0008-0

Srivastava, A., Singh, V., Haque, S., Pandey, S., Mishra, M., Jawed, A., Shukla, P.K., Singh, P.K. \& Tripathi, C.K.M. (2018b). Response Surface MethodologyGenetic Algorithm Based Medium Optimization, Purification, and Characterization of Cholesterol Oxidase from Streptomyces rimosus. Scientific Reports ,8:10913. https://doi.org/10.1038/s41598-018-29241-9

Tabatabaei, M., Malekzadeh, F., Zarrini, G.H., Faramarzi, M.A. \& Kamranpour, N. (2001). Production of cholesterol oxidase by a newly isolated Rhodococcus sp. World Journal of Microbiology and Biotechnology, 17, 731737.https://doi.org/10.1023/A:1012993532686

Varma, R. \& Nene, S. (2003). Biosynthesis of cholesterol oxidase by Streptomyces lavendulae NCIM 2421. Enzyme and Microbial Technology, 33, 286-291. https://doi.org/10.1016/S0141-0229(03)00126-1 